Citation: M. Minutolo, M. Cinque, G. Altamura, F. Di Serio, D. Alioto, B. Navarro (2021) Identification, full-length genome sequencing, and field survey of citrus vein enation virus in Italy. Phytopathologia Mediterranea 60(2): 293-301. doi: 10.36253/phyto-12180

Accepted: March 5, 2021

Published: September 13, 2021

Copyright: (C2021 Author. This is an open access, peer-reviewed article published by Firenze University Press (http:// www.fupress.com/pm) and distributed under the terms of the Creative Commons Attribution License, which permits unrestricted use, distribution, and reproduction in any medium, provided the original author and source are credited.

Data Availability Statement: All relevant data are within the paper and its Supporting Information files.

Competing Interests: The Author(s) declare(s) no conflict of interest.

Editor: Anna Maria D'Onghia, CIHEAM/Mediterranean Agronomic Institute of Bari, Italy.

\section{Short Notes \\ Identification, full-length genome sequencing, and field survey of citrus vein enation virus in Italy}

\author{
Maria MinUtOlO ${ }^{1}$, Maria CinQUe ${ }^{1}$, Giuseppe AltamURA ${ }^{2}$, \\ Francesco Di SERIO ${ }^{2}$, DANiela AliOTO ${ }^{1}$, Beatriz NAVARRO ${ }^{2, *}$ \\ ${ }^{1}$ Dipartimento di Agraria, Università degli Studi di Napoli Federico II, Portici (NA), Italy \\ ${ }^{2}$ Istituto per la Protezione Sostenibile delle Piante, Consiglio Nazionale delle Ricerche, \\ Bari, Italy \\ ${ }^{\star}$ Corresponding author. E-mail: beatriz.navarro@ipsp.cnr.it
}

Summary. Citrus vein enation virus (CVEV) was described in Spain and then it has been reported in several citrus growing areas of Asia, America and Australia. Here, the occurrence of CVEV in Italy has been documented for the first time. The full genome sequence of a CVEV Italian isolate (14Q) was determined by high-throughput sequencing and the presence of the virus was confirmed by RT-PCR and graft-transmission to indicator plants, from which the virus was recovered six-months post-inoculation. Phylogenetic analysis based on the full-length genome of CVEV isolates from different countries showed that they are phylogenetically related to each other based on their geographic origin, rather than on their host and that the Italian isolate is more closely related to the Spanish isolate than to the other ones. A field survey revealed the presence of CVEV in some areas of Campania region (southern Italy), prevalently infecting lemon trees. In the frame of this survey, kumquat was identified for the first time as a host of CVEV. No symptoms were observed in the field so far. The infection of asymptomatic hosts and the transmission by aphid species present in Italy increase the risk that the virus could further spread.

Keywords. Citrus virus, vein enation disease, woody gall disease, CVEV.

\title{
INTRODUCTION
}

Citrus vein enation virus (CVEV), a monopartite, single strand positive sense RNA virus (Luteoviridae, Enamovirus), has been proposed as the causal agent of citrus vein enation (VE) and woody gall (WG) (Vives et al., 2013). These two graft-transmissible citrus diseases were first described in United States of America in sour orange (VE) and in Australia in rough lemon (WG) (Wallace \& Drake, 1953; Fraser, 1959; Moreno, 2000). Although CVEV may remain latent in several commercial citrus cultivars, it has been found associated with small outgrow in the underside tissues of leaves (enations), mainly in correspondence to secondary veins, of some susceptible citrus species, such as Mexican lime [Citrus aurantifolia (Christm.) Swingle], sour 
orange (C. aurantium L.), C. junos Siebold ex Tanaka, citron (C. medica L.), satsuma (C. $x$ unshiu) and various local Chinese citrus varieties (Chen et al., 1992). Woody gall disease, characterized by galls on trunks and/or branches, has been reported in Rangpur lime (C. $x$ limonia Osbeck), rough lemon (C. jambhiri Lush), and C. $x$ volkameriana rootstocks (Fraser, 1959). Based on bioassays, it was shown that both VE and WG diseases were caused by the same transmissible agent (Wallace and Drake, 1960), now identified as CVEV (Vives et al., 2013). This virus is transmitted in a persistent manner by several aphid species, including Toxoptera citricidus, Myzus persicae and Aphis gossypii, (Hermoso de Mendoza et al., 1993; Maharaj and da Graca, 1989) and is considered a quarantine pest in several Mediterranean and American countries (https://gd.eppo.int/taxon/CVEV00/ categorization). The complete genome of twenty CVEV isolates from six countries (Spain, Japan, China, South Korea, United States of America and Australia) has been sequenced (Vives et al., 2013; Huang et al., 2015; Nakazono-Nagaoka et al., 2017; Wu et al., 2019; Yang et al., 2019). Although VE disease is widespread in Spain, it has not been reported in Italy (Catara and Davino, 1984). Spain is the only European country where the CVEV has been identified and characterized (Vives et al., 2013).

High-throughput sequencing (HTS) is the most effective technology for detection of viruses in plants (Maliogka et al., 2018). This has allowed identification of several novel viruses in citrus hosts (Loconsole et al., 2012a; Loconsole et al., 2012b; Roy et al., 2013; Vives et al., 2013; Harakava et al., 2017; Ramos-González et al., 2017; Chabi-Jesus et al., 2018; Navarro et al., 2018a; Navarro et al., 2018b; Chabi-Jesus et al., 2020; Wu et al., 2020; Xuan et al., 2020). The present study, based on HTS data, reports the first identification of CVEV in Italy. The complete genome sequence and variability of the Italian CVEV isolate is also presented, together with the results of graft-transmission bioassays. In addition, data are reported on the spread of this virus mainly in Campania region (Southern Italy), where lemons are important citrus crops.

\section{MATERIALS AND METHODS}

Plant material, RNA preparation and high-throughput sequencing of cDNA libraries

Fresh flushes, collected in 2018 from a non-symptomatic sweet orange tree (Citrus sinensis, L.) grown in Campania region, were used for generating a cDNA library. Total RNA was extracted with phenol/chloroform (Pallás et al., 1987) followed by elimination of pol- ysaccharides with the methoxyethanol method (Bellami and Ralph, 1968). After DNase treatment and ribosomal RNA depletion (Navarro et al., 2018a), cDNA libraries were constructed using the Illumina TruSeq Total stranded RNA Sample Preparation Kit, according to the manufacturer's protocol. HTS was performed in a NextSeq500 analyzer (Illumina) with a configuration of 150 paired ends reads. After removing the reads mapping in the host genome, high quality reads were de novo assembled using SPAdes software (Bankevich et al., 2012). The obtained contigs were screened by BlastN and BlastX for homologous viral sequences in the National Center for Technology Information (NCBI). Alignments of HTS reads to the reference genome of CVEV (NC-021564) were performed by Bowtie (Langmead et al., 2009) implemented in the MacVector Assembler platform (15.1.5, MacVector, Inc.).

\section{RT-PCR detection, field survey and bioassays}

Total nucleic acids (100 ng) were extracted and reverse transcribed as reported previously (Navarro et al., 2017). Two $\mu \mathrm{L}$ of the cDNA reaction were used for the PCR amplification in a reaction volume of $25 \mu \mathrm{L}$, using 1.25 units of GoTaq polymerase (Promega) and containing final concentrations of $0.2 \mu \mathrm{M}$ of each primer. The two CVEV specific primer pairs VE5f /VE15r and VE16f/VE17r, previously reported by Vives et al. (2013) and targeting a CVEV genomic region coding for the polymerase and the coat protein, respectively, were used. The cycling conditions were as follows: initial denaturation at $94^{\circ} \mathrm{C}$ for $3 \mathrm{~min}$, followed by 32 cycles at $94^{\circ} \mathrm{C}$ for $30 \mathrm{~s}, 55^{\circ} \mathrm{C}$ for $30 \mathrm{~s}, 72^{\circ} \mathrm{C}$ for $30 \mathrm{~s}$, and a final extension step at $72^{\circ} \mathrm{C}$ for $7 \mathrm{~min}$. The reaction products were analysed by electrophoresis on $2 \%$ agarose gels buffered in TAE (0.04 M Tris-acetate, $1 \mathrm{mM}$ EDTA, pH 8) and visualized by UV light after ethidium bromide staining. Amplicons were purified, cloned in pGemTeasy (Promega) and sequenced (Macrogen).

A field survey was carried out in spring 2019 in 14 orchards (13 located in provinces of Campania region and one in Latina province of Lazio region). Leaves from fresh flushes from sweet orange [Citrus sinensis (L.) Osbeck], clementine (C. clementina Hortex Ex Tanaka), lemon [C. x limon (L.) Burm. f.], mandarin (C. reticulata Blanco), kumquat (C. japonica Thunb.), tangerine (C. $x$ tangerina), grapefruit (C. $x$ paradisi Macfad.), sour orange, or citron (C. medica L.) trees were analyzed by RT-PCR (as outlined above) using the primer pair VE5f/ VE15r. Bioassays were performed by grafting bark tissues from the Italian isolate to three sour orange indicator plants grown at $23-25^{\circ} \mathrm{C}$ in a greenhouse, which were 
then maintained under observation for two consecutive years (Roistacher, 1991).

\section{Phylogenetic analysis}

Sequence variability within the CVEV-14Q isolate was investigated by identifying the SNPs using Bowtie (Langmead et al., 2009). Multiple alignments of the fullgenome, 5'UTR and 3'UTR nucleotide (nt) sequence, of the amino acid sequence of the putative proteins encoded by the Italian CVEV isolate, and with those available in databases were performed using Clustal Omega (Sievers and Higgings, 2014). A pairwise matrix was generated from each alignment. The multiple alignment of the genomic sequence was used to generate a phylogenetic tree by maximum likelihood method with the best-fit model of kimura- $2+\mathrm{G}$ and 1000 bootstraps inferred in the MEGA7 package.

\section{RESULTS AND DISCUSSION}

\section{Identification of an Italian isolate of $\mathrm{CVEV}$}

To characterize citrus viromes in the Campania region (southern Italy), a cDNA library of total RNAs from a non-symptomatic sweet orange tree (isolate 14Q) was analyzed by HTS. A total of $24,800,000$ high quality reads were obtained, and after removing those mapping in the citrus genome (nuclear, chloroplastic and mitochondrial genomes), the remaining 8,510,000 reads were assembled in contigs. BlastN search with the obtained contigs allowed identification of 11 contigs sharing high sequence similarity to CVEV (97 to $99 \%$ nt identity). When mapped on the CVEV genome, the contigs covered $84 \%$ of the viral genome, indicating a possible infection of the source tree by this virus. The presence of CVEV in the original tree $14 \mathrm{Q}$ was confirmed by RTPCR using two primer pairs (VE5f /VE15r and VE16f/ VE17r) specific for this virus and already reported in the literature (Vives et al., 2013). PCR amplicons with the expected size of 426 and 413 nt were obtained using total RNA extracted from leaf samples collected from the 14Q tree during two consecutive springs (in 2018 and 2019). Cloning and Sanger sequencing of the generated PCR fragments confirmed that they had 100\% nt identity with the corresponding CVEV sequences obtained by HTS. These data confirmed the CVEV infection by a second and independent detection method. This is the first report of CVEV in Italy.

The transmissibility of the CVEV-14Q isolate was tested by graft-inoculating bark tissues from the origi- nal infected sweet orange tree onto three seedlings of sour orange indicator. RT-PCR assay using VE5f/VE15r oligonucleotides showed that all the inoculated plants were infected by CVEV 6 months post-inoculation. No enations and no wood alterations were observed in the infected plants periodically inspected for symptom expression for more than 2 years after the graft-inoculation. However, additional bioassays with a greater number of tested plants and the other susceptible indicators rough lemon and Mexican lime must be performed to determine the pathogenicity of the CVEV-14Q isolate.

Characterization of the full-length genome of an Italian isolate of $C V E V$

Alignments of sequenced reads on the reference CVEV genome (VE-1 isolate, NC_021564) using the Bowtie software, allowed assembly of the consensus fulllength genomic sequence (mean coverage depth $=33$ ) of the first Italian CVEV isolate. This was named CVEV14Q (Genbank ID: MW167082) (Figure 1a).

The CVEV-14Q genome is $5983 \mathrm{nt}$ long, with the same organization of the reference isolate VE-1, and consists of five ORFs surrounded by a 5' untranslated region (UTR) and a 3'UTR (Figure 1b). The overlapping ORF0, ORF1 and ORF2 were very likely directly translated from the genomic RNA, while the expression of ORF3 and ORF5 is proposed to occur through the synthesis of a 3' co-terminal subgenomic RNA (Vives et al., 2013). The abundance of this subgenomic RNA in the nucleic acid preparations used for generating the RNA seq library could justify the asymmetric distribution of the sequenced reads on the CVEV genome, with a prevalent coverage in the 3 ' region including ORF3 and ORF5 (Figure 1a). ORF0 (positions 219-1283) overlaps completely with ORF1, and encodes a putative protein of $39 \mathrm{kDa}(\mathrm{P} 0)$ that likely is a suppressor of gene silencing (Vives et al., 2013). P0 contains the four conserved amino acids $(\operatorname{Lxxx}(\mathrm{L} / \mathrm{I}) \times 10-13 \mathrm{P})$ of a putative F-boxlike motif (Huang et al., 2015). ORF1 (positions 2082016) encodes for a putative peptidase of $100 \mathrm{kDa}$ that contains the conserved serine proteinase domain characteristic of the S39 peptidase superfamily. The ORF2 (positions 2202-4148) is translated via a -1 ribosomal frameshift of ORF1, thus encoding a putative fusion protein of $148 \mathrm{kDa}$ that contains the conserved polymerase and helicase domains (replicase). ORF3 (positions 43014876) codes for the putative coat protein (CP) of $21 \mathrm{kDa}$. ORF5 (positions 4301-5785) is translated by an in-frame readthrough of the amber stop codon of ORF3 allowing the expression of a putative fusion protein (P5) of 55 $\mathrm{kDa}$, which is probably involved in aphid transmission, 
a

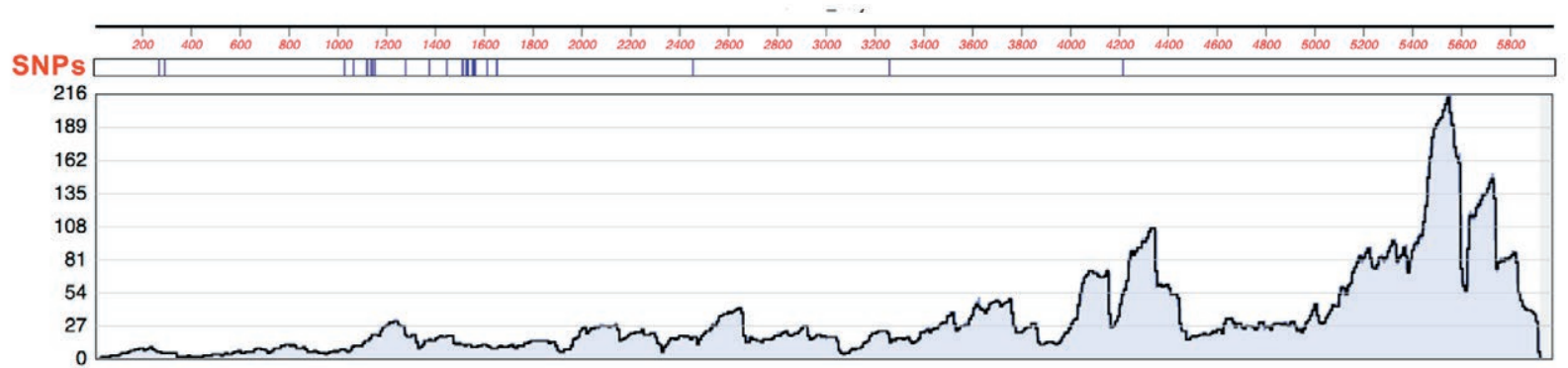

b

\section{CVEV genomic RNA}
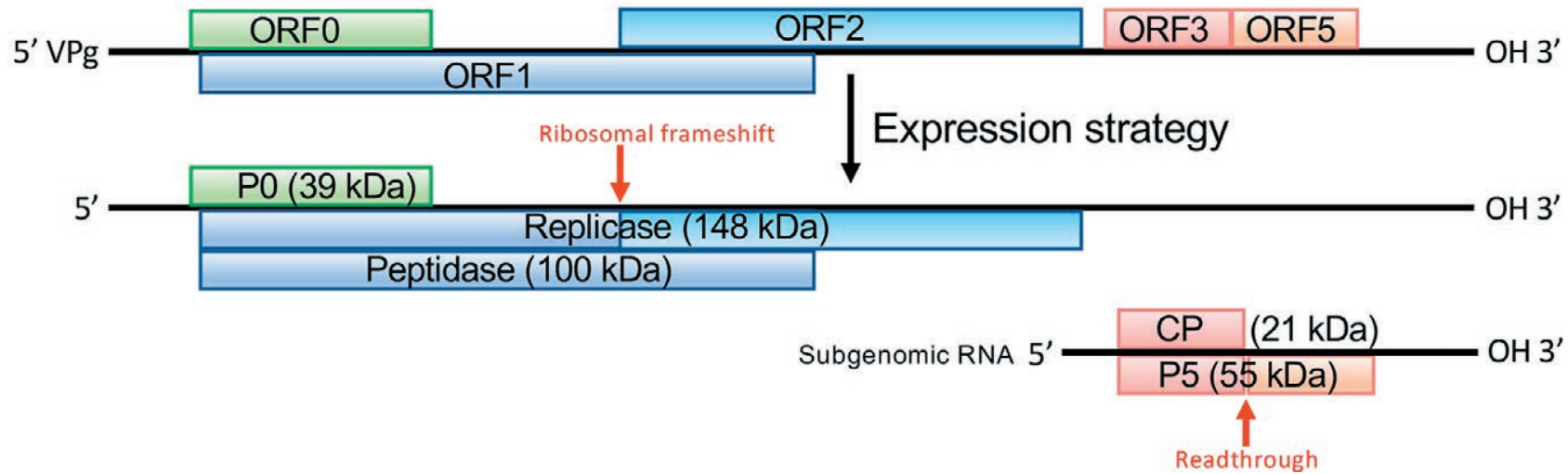

Figure 1. (a) CVEV genome coverage by HTS reads. Alignments were performed using the Bowtie program and the CVEV variant NC_021564 as the reference sequence. Nucleotide (nt) positions are indicated at the top. Single nucleotide polymorphisms (SNPs) are indicated by vertical lines below the respective positions. (b) Genome organization and expression strategy of CVEV. Putative ORFs are indicated by boxes. The predicted proteins expressed from the genomic and subgenomic RNAs are indicated by boxes in the lower part of the panel.

symptom expression and virus accumulation (Vives et al., 2013).

Sequence variability within the CVEV-14Q isolate was investigated by aligning the HTS reads on CVEV$14 \mathrm{Q}$ consensus genome using Bowtie. This identified a total of 26 variable nucleotide positions in the CVEV genome of the 14Q virus isolate (Figure 1a; Table 1). Most of them were located between the positions 267 and 1651, which include the ORF0 overlapping with a fragment of ORF1 and a region of ORF1 not overlapping with other ORFs. Since in a sequence with overlapping ORFs one nucleotide change can differently affect the encoded proteins, we further considered the 10 mutations observed in the overlapping ORF0-ORF1 region. Most mutations were synonymous in P0 (six out of ten) and non-synonymous in the peptidase (nine out of ten). These data suggest that the nucleotide variability in this region has a greater effect on the amino acid variability in the peptidase than in the P0. Two other variable positions were identified in the replicase coding region and in the intergenic region. Although several of the mutations observed in the CVEV-14Q isolate were also identified in other CVEV isolates, most of the mutations are here reported for the first time (Table 1).

Phylogenetic relationships between CVEV-14Q and other reported isolates

Pairwise alignment of the CVEV-14Q full-length genome with genomes of the other 20 isolates that have been characterized from different geographic areas, revealed the greatest similarity $(99.08 \%$ of nt identity) with the isolate VE-1 from Spain, and the least (97.09\%) with the CVEV SM isolate from China (Figure 2). The 5' UTR region of CVEV-14Q, showing the least similarity $(92.75 \%$ of nt identity) with the Chinese SM iso- 


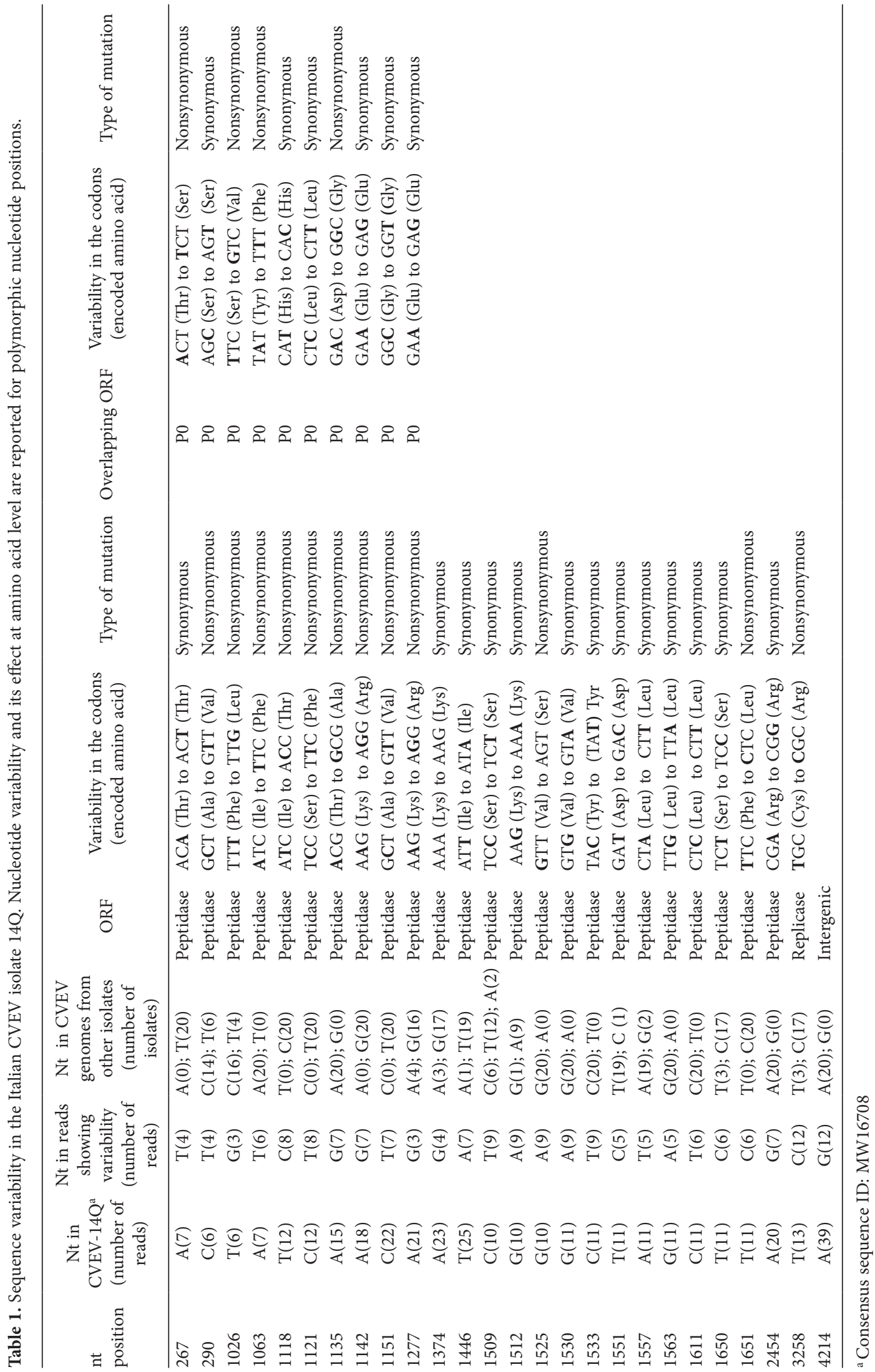




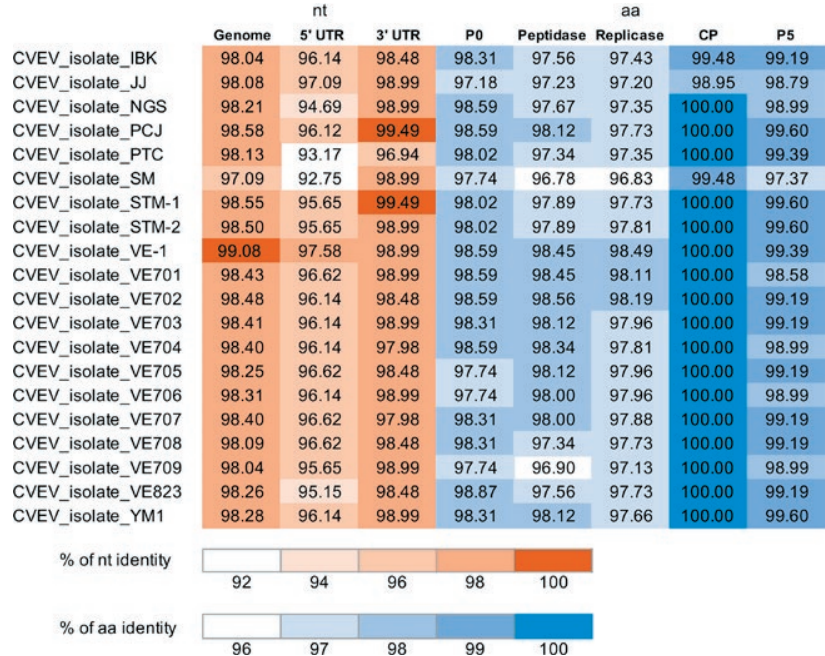

Figure 2. Percentage of nucleotide (nt) and amino acid (aa) sequence identity between the CVEV Italian isolate $14 \mathrm{Q}$ and fulllength CVEV isolates in databases. Scales of colour identify similar nt and aa identity scores. The accession numbers of the virus isolates are reported in Figure 3.

late, was more divergent than the 3'UTR from the other sequenced isolates. Amino acid sequence comparisons between homologous proteins (Figure 2) identified the putative peptidase protein and the replicase as the proteins of CVEV-14Q that mostly differed from the other isolates, especially from the Chinese isolate SM $(96.78 \%$ aa identity with the putative peptidase protein and $96.83 \%$ aa identity with the replicase). The putative CP is the most conserved protein among the studied isolates, with the exception of the slightly divergent isolates SM from China (99.48\% aa identity), IBK from Japan (99.48\% aa identity) and JJ from Korea (98.95\% aa identity). The other predicted proteins P0 and P5 also showed high sequence similarities with the respective proteins encoded by other isolates.

Although not yet associated with any biological roles, amino acid changes in some CVEV isolates have been previously highlighted (Nakazono-Nagaoka et al., 2017). Four amino acid residues, at positions 83, 104 and 113 of ORF2 and position 41 of ORF5, have been proposed as differential residues among Spanish and Japanese isolates (Nakazono-Nagaoka et al., 2017). Like the Spanish isolates, the CVEV-14Q has a leucine and an arginine at positions 83 and 104 of the protein encoded in ORF2, whereas most of the other known CVEV isolates have a phenylalanine and a glycine at the same positions. The exception is isolate VE823, which also has an arginine at position 104 (Supplementary Figure 1). The amino acid at position 113 of ORF2 is a valine in most isolates, except in the Italian isolate 14Q (a threo- nine in this position), the Spanish isolate VE-1 (an isoleucine) and the Korean isolate JJ (an alanine). The serine at the position 41 of ORF5 remains specific of the Spanish isolates since in all the other CVEV characterized, including the Italian CVEV-14Q, there is an arginine at that position. Therefore, although closely related to each other, the Italian and Spanish isolates had some diversity.

Relationships between CVEV isolate $14 \mathrm{Q}$ and virus isolates from different geographic areas and host species were investigated by generating a maximum likelihood phylogenetic tree using the available full-genomic sequences of the virus (Figure 3). The Italian 14Q and the Spanish VE-1 isolates clustered together. All CVEV isolates from the United States of America were grouped in the same clade, and those from Japan and South Korea clustered in the same phylogenetic subgroup. The CVEV isolate VE709 from Australia was related to the phylogenetic subgroup of American isolates, whereas the isolate from China was unrelated to the other CVEV clades. Therefore, CVEV isolates grouped according to their geographic origins, rather than their host species, indicating a minor role of hosts in the genetic diversity of CVEV isolates.

\section{Field survey}

Thirteen citrus growing areas of the Campania region and one on Latium region, at the northwest border of Campania (Suio, Latina Province), were surveyed. In Campania, the most common citrus species are sweet orange and lemon, which are widely grown in commercial citrus orchards as well as in private and public gardens. A total of 229 citrus trees of different species were tested by RT-PCR. The assays showed that 32 tree samples (14.0\%) were infected by CVEV, with lemon trees showing the greatest incidence $(26.4 \%)$ (Table 2). This is the first report of CVEV in Kumquat (https://gd.eppo. int/taxon/CVEV00), but only one of two plants analysed, collected from a household garden, tested positive. The tangerine, grapefruit, sour orange, and citron trees from Campania region analyzed in the survey tested negative for CVEV infections. However, in these cases, only very few plants of each host species were tested. None of the infected trees showed the typical symptoms of VE or WG that have been reported to be associated to CVEV in some citrus species. This agrees with previous data reporting symptomless infections of CVEV in lemon, mandarin and orange (Catara and Davino, 1984).

When the geographic distribution of infected samples was considered, the positive samples were only from some areas (mainly in Naples and Salerno province). 


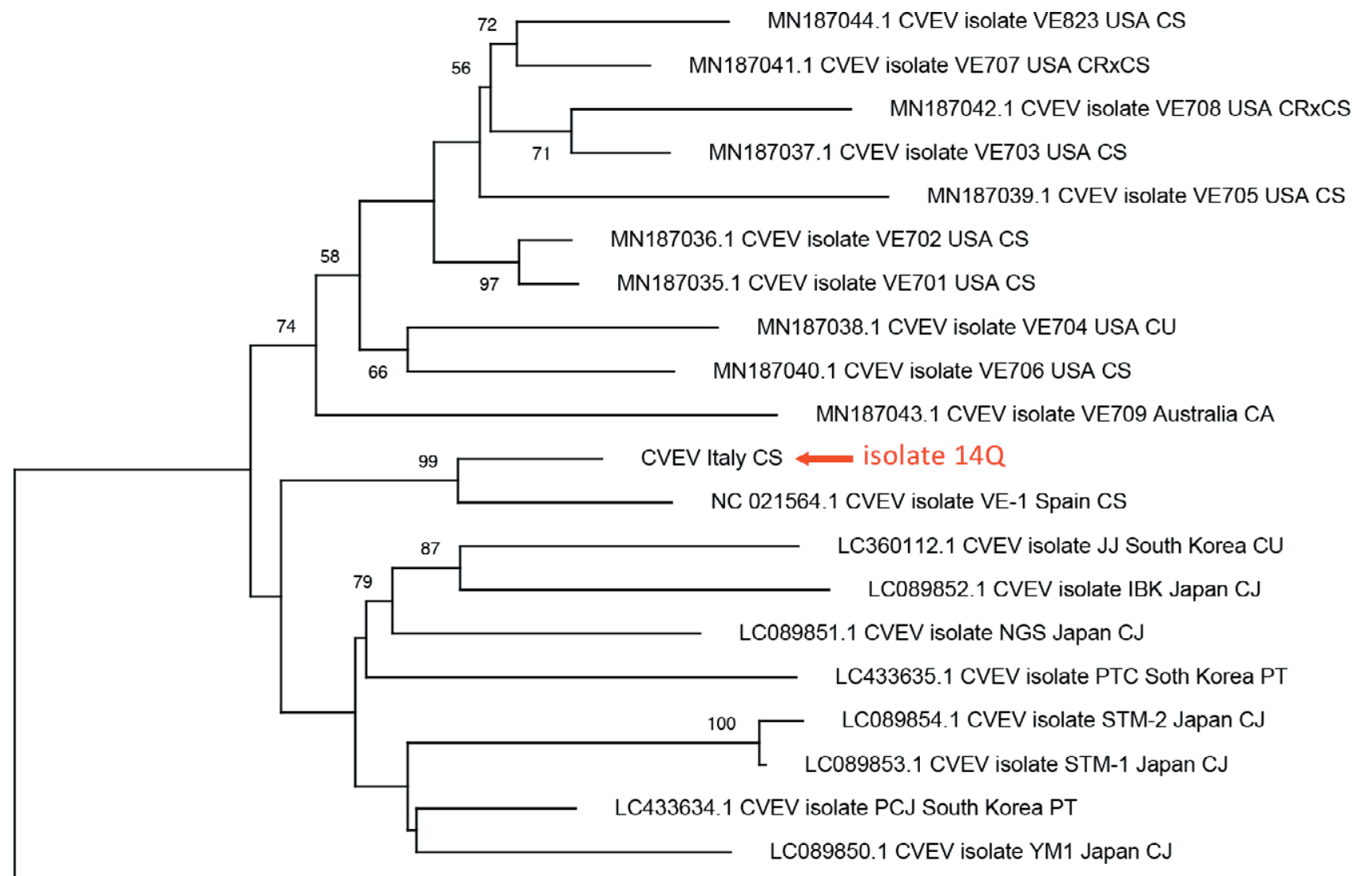

KY303624.1 CVEV isolate SM China CM

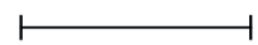

0.0050

Figure 3. Phylogenetic tree generated using all the full-length CVEV genome sequences available in databases and the CVEV-14Q isolate. Clustal omega alignment of the nucleotide sequences was used for inferring the phylogenetic tree using the Maximum likelihood method, and adopting the best-fit model kimura 2+G using MEGA7. Bootstrap probability values (1000 replicates) greater than $50 \%$ are shown at the branch nodes. Tree branches are proportional to the genetic distances, with the scale bar indicating substitutions per nucleotide site. The accession number, isolate name, country of origin and citrus host (Citrus junos, CJ; C. maxima, CM; C. reticulata, CR; C. sinensis, CS; C. unshiu, CU; Poncirus trifoliata, PT) are shown at each branch tip.

These data indicate that CVEV is not widespread in the surveyed area. However, since this virus is transmitted by several aphid species (Hermoso de Mendoza et al., 1993; Maharaj and da Graça, 1989), two of which, Myzus persicae and Aphis gossypii, are present in the surveyed area, the virus will likely be further disseminated. Asymptomatic infected citrus trees can also be sources of inoculum if used for vegetative propagation. Detection of CVEV in a symptomless kumquat tree is important. The trees are mainly grown in pots as ornamental plants, so they could favour long distance virus spread. Extension of CVEV surveys to a greater number of kumquat trees and to other ornamental citrus species would be worthwhile.
Inclusion of CVEV in the list of quality-affecting organisms in the Italian programs for certification of citrus propagation material is strongly recommended, as the present study has demonstrated that several citrus species can be infected by CVEV.

\section{ACKNOWLEDGEMENTS}

This research was partially supported by the projects 'URCOFI' (funded by Regione Campania, DGR 690/2016, 6th December 2016), and 'INNOCI' (funded by Regione Puglia, DGR n. 903/ 2012, 15th May 2012). The project also received funding from the European 
Table 2. Survey of citrus vein enation virus in different orchards of Campania region and one orchard of Latina province. Number of CVEV infected trees /number of total trees analyzed is shown.

\begin{tabular}{|c|c|c|c|c|c|c|c|c|c|c|}
\hline Geographic area (Province) & $\begin{array}{c}\text { Total } \\
\text { citrus } \\
\text { trees }\end{array}$ & Lemon & $\begin{array}{l}\text { Sweet } \\
\text { orange }\end{array}$ & Mandarin & Clementine & Kumquat & Tangerin & Grapefruit & $\begin{array}{c}\text { Sour } \\
\text { orange }\end{array}$ & Citron \\
\hline Averno (Naples) & $1 / 6$ & $1 / 6$ & - & - & - & - & - & - & - & - \\
\hline San Antonio Abbate (Naples) & $3 / 19$ & - & $1 / 8$ & $2 / 10$ & $0 / 1$ & - & - & - & - & - \\
\hline Agnano (Naples) & $0 / 2$ & - & - & - & $0 / 2$ & - & - & - & - & - \\
\hline Casoria (Naples) & $12 / 23$ & $8 / 9$ & $2 / 7$ & $1 / 4$ & - & $1 / 2$ & $0 / 1$ & - & - & - \\
\hline Ercolano (Naples) & $1 / 8$ & $1 / 2$ & $0 / 1$ & $0 / 4$ & $0 / 1$ & - & - & - & - & - \\
\hline Napoli (Naples) & $3 / 8$ & $3 / 3$ & - & $0 / 1$ & $0 / 2$ & - & - & - & $0 / 2$ & - \\
\hline Ponticelli (Naples) & $2 / 10$ & $1 / 3$ & $1 / 3$ & $0 / 1$ & $0 / 3$ & - & - & - & - & - \\
\hline Maddaloni (Caserta) & $0 / 16$ & - & $0 / 7$ & $0 / 8$ & $0 / 1$ & - & - & - & - & - \\
\hline Sta Maria Capua Vetere (Caserta) & $0 / 10$ & - & $0 / 8$ & $0 / 2$ & - & - & - & - & - & - \\
\hline Maiori (Salerno) & $1 / 13$ & $1 / 13$ & - & - & - & - & - & - & - & - \\
\hline Minori (Salerno) & $8 / 26$ & $8 / 26$ & - & - & - & - & - & - & - & - \\
\hline Eboli (Salerno) & $0 / 47$ & $0 / 15$ & $0 / 26$ & - & $0 / 2$ & - & $0 / 2$ & $0 / 2$ & - & - \\
\hline Pontecagnano (Salerno) & $0 / 11$ & $0 / 5$ & $0 / 1$ & $0 / 1$ & $0 / 2$ & - & - & - & $0 / 1$ & $0 / 1$ \\
\hline Suio (Latina) & $1 / 30$ & $0 / 5$ & $1 / 15$ & $0 / 6$ & $0 / 4$ & - & - & - & - & - \\
\hline Total & $\begin{array}{l}32 / 229 \\
(14.0 \%)\end{array}$ & $\begin{array}{c}23 / 87 \\
(26.4 \%)\end{array}$ & $\begin{array}{c}5 / 76 \\
(6.5 \%)\end{array}$ & $\begin{array}{c}3 / 37 \\
(8.1 \%)\end{array}$ & $0 / 18(0 \%)$ & $1 / 2(50 \%)$ & $0 / 3(0 \%)$ & $0 / 2(0 \%)$ & $0 / 3(0 \%)$ & $0 / 1(0 \%)$ \\
\hline
\end{tabular}

Union's Horizon 2020 research and innovation program under the Marie Skłodowska-Curie grant agreement No. 734736. This paper reflects only the authors' views, and the Agencies are not responsible for any use that may be made of the information it contains.

\section{LITERATURE CITED}

Bellamy A.R., Ralph R.K., 1968. Recovery and purification of nucleic acids by means of cetyl trimethylammonium bromide. Methods in Enzymology XII: 156160.

Bankevich A., Nurk S., Antipov D., Gurevich A.A., Dvorkin M., ... Pevzner P.A., 2012. SPAdes: a new genome assembly algorithm and its applications to single-cell sequencing. Journal of Computational Biology 19: 455-477. https://doi.org/10.1089/cmb.2012.0021.

Catara A., Davino M., 1984. Citrus diseases not found in Italy, caused by viruses and virus-like pathogens. Informatore Fitopatologico 34: 9-21.

Chabi-Jesus C., Ramos-González P.L., Tassi A.D., GuerraPeraza O., Kitajima E.W., ... Freitas-Astúa J., 2018. Identification and Characterization of Citrus Chlorotic Spot Virus, a New Dichorhavirus Associated with Citrus Leprosis-Like Symptoms. Plant Disease 102: 15881598. https://doi.org/10.1094/PDIS-09-17-1425-RE.

Chabi-Jesus C., Najar A., Fontenele R.S., Kumari S.G., Ramos-González P.L., ... Varsani A., 2020. Viruses representing two new genomovirus species identified in citrus from Tunisia. Archives in Virology 165: 1225-1229. https://asu.pure.elsevier.com/en/publications/viruses-representing-two-new-genomovirusspecies-identified-in-ci.

Chen G.Q., Yan S.X., Roistacher C.N., 1992. First report of citrus vein enation disease in China. Plant Disease 76: 1077. https://www.apsnet.org/publications/ plantdisease/backissues/Documents/1992Abstracts/ PD_76_1077C.htm

Fraser L. R., 1959. Woody gall, a suspected virus disease of rough lemon and other citrus varieties. Proceedings of the Linnean Society of New South Wales 84: 332-336.

Harakava R., Salaroli R.B., Freitas-Astúa J., 2017. Citrus leprosis virus N: A New Dichorhavirus Causing Citrus Leprosis Disease. Phytopathology 107: 963-976. https://doi.org/10.1094/PHYTO-02-17-0042-R

Hermoso de Mendoza A., Pina J.A., Ballester-Olmos J.F., Navarro L., 1993. Persistent transmission of Citrus vein enation virus by Aphis gossypii and Myzus persicae. In: Proc. 12th Conf. Intern. Organization Citrus Virol. (P. Moreno, J. V. da Graça, and L. W. Timmer, ed.), IOCV, Riverside, CA, USA: 361-362.

Huang A., Song Z., Cao M., Chen H., Li Z., Zhou C., 2015. The complete genome sequence of Citrus vein enation virus from China. Journal of Integrative Agriculture 14: 598-601. https://doi.org/10.1016/S20953119(14)60903-5 
Langmead B., Trapnell C., Pop M., Salzberg S.L., 2009. Ultrafast and memory-efficient alignment of short DNA sequences to the human genome. Genome Biology 10: R25. https://genomebiology.biomedcentral. com/articles/10.1186/gb-2009-10-3-r25

Loconsole G., Onelge N., Potere O., Giampetruzzi A., Bozan O., ... Saponari M., 2012a. Identification and characterization of citrus yellow vein clearing virus, a putative new member of the genus Mandarivirus. Phytopathology 102: 1168-175. https://apsjournals. apsnet.org/doi/pdf/10.1094/PHYTO-06-12-0140-R

Loconsole G., Saldarelli P., Doddapaneni H., Savino V., Martelli G.P., Saponari M., 2012b. Identification of a single-stranded DNA virus associated with citrus chlorotic dwarf disease, a new member in the family Geminiviridae. Virology 432: 162-172. https://doi. org/10.1016/j.virol.2012.06.005

Maliogka V.I., Minafra A., Saldarelli P., Ruiz-García A.B., Glasa M., ... Olmos A., 2018 Recent Advances on Detection and Characterization of Fruit Tree Viruses Using High-Throughput Sequencing Technologies. Viruses 10: 436. https://doi.org/10.3390/v10080436

Maharaj S.B., da Graça J.V., 1989. Transmission of citrus vein enation virus by Toxoptera citricidus. Phytophylactica 21: 81-82.

Moreno P., 2000. Protuberancias nerviales-Agallas de la madera (Vein enation-Woody gall). In: Enfermedades de los citricos. Monografía de la Sociedad Española de Fitopatología no. 2 (N. Duran- Vila and P. Moreno, ed.), Ediciones Mundi-Prensa, Madrid, Spain: 74-75.

Nakazono-Nagaoka E., Fujikawa T., Iwanami T., 2017. Nucleotide sequences of Japanese isolates of citrus vein enation virus. Archives in Virology 62: 879-883. doi: 10.1007/s00705-016-3139-6. https://link.springer.com/article/10.1007/s00705-016-3139-6

Navarro B., Loconsole G., Giampetruzzi A., Aboughanem-Sabanadzovic N., Ragozzino A., ... Di Serio F., 2017. Identification and characterization of privet leaf blotch-associated virus, a novel idaeovirus. Molecular Plant Pathology 18: 925-936. https://doi.org/10.1111/ mpp. 12450

Navarro B., Minutolo M., De Stradis A., Palmisano F., Alioto D., Di Serio F., 2018a. The first phlebo-like virus infecting plants: a case study on the adaptation of negative-stranded RNA viruses to new hosts. Molecular Plant Pathology 19: 1075-1089. https://doi. org/10.1111/mpp.12587

Navarro B., Zicca S., Minutolo M., Saponari M., Alioto D., Di Serio F., 2018b. A Negative-Stranded RNA Virus Infecting Citrus Trees: The Second Member of a New Genus Within the Order Bunyavirales. Fron- tiers in Microbiology 9: 2340. https://doi.org/10.3389/ fmicb.2018.02340.

Pallás V., Navarro A., Flores R., 1987. Isolation of a viroid-like RNA from hop different from hop stunt viroid. Journal of General Virology 68: 2095-2102.

Ramos-González P.L., Chabi-Jesus C., Guerra-Peraza O., Tassi A.D., Kitajima EW, ... Freitas-Astúa J., 2017. Citrus leprosis virus N: A New Dichorhavirus Causing Citrus Leprosis Disease. Phytopathology 107: 963976. https://doi.org/10.1094/PHYTO-02-17-0042-R

Roistacher, C.N. 1991. Graft transmissible diseases of citrus. In: Handbook for Detection and Diagnosis, F.A.O., Rome.

Roy A., Choudhary N., Guillermo L.M., Shao J., Govindarajulu A., ... Brlansky R.H., 2013. A novel virus of the genus Cilevirus causing symptoms similar to citrus leprosis. Phytopathology 103: 488-500. https://apsjournals.apsnet.org/doi/pdf/10.1094/PHYTO-07-12-0177-R

Sievers F., Higgins D.G., 2014. Clustal Omega, accurate alignment of very large numbers of sequences. Methods in Molecular Biology 1079: 105-116. https://link. springer.com/protocol/10.1007/978-1-62703-646-7_6

Vives M.C., Velázquez K., Pina J.A., Moreno P., Guerri J., Navarro L., 2013. Identification of a new enamovirus associated with citrus vein enation disease by deep sequencing of small RNAs. Phytopathology 103: 10771086. https://doi.org/10.1094/PHYTO-03-13-0068-R

Wallace J.M., Drake R., 1953. A virus-induced vein enation in citrus. Citrus Leaves 33: 22-24.

Wallace J.M., Drake R.J., 1960. Woody galls on citrus associated with vein-enation virus infection. Plant Disease Reporter 44: 580-584.

Wu J., Liu Q., Qiu Y., Zhang S., Li Z., ... Cao M., 2019. First Report of Citrus Vein Enation Virus from Citrus Cultivar Huangguogan in Sichuan Province, China. Plant Disease 103. https://apsjournals.apsnet.org/ doi/10.1094/PDIS-03-19-0461-PDN

Wu J., Zhang S., Atta S., Yang C., Zhou Y., ... Cao M., 2020. Discovery and Survey of a New Mandarivirus Associated with Leaf Yellow Mottle Disease of Citrus in Pakistan. Plant Disease 104: 1593-1600. https:// doi.org/10.1094/PDIS-08-19-1744-RE

Xuan Z., Li S., Zhang S., Ran W., Zhou Y., ... Cao M., 2020. Complete genome sequence of citrus yellow spot virus, a newly discovered member of the family Betaflexiviridae. Archives in Virology 165: 2709-2713. https://link. springer.com/article/10.1007/s00705-020-04794-1

Yang H.J., Oh J., Lee H.K., Lee D. S., Kim S.Y., ... Lee S.H., 2019. First Report of Citrus Vein Enation Virus in Satsuma Mandarin (Citrus unshiu) in Korea. Plant Disease 103: 2703. https://doi.org/10.1094/PDIS-0319-0468-PDN 